\title{
Production of exopolysaccharides by Lactobacillus and Bifidobacterium strains of human origin, and metabolic activity of the producing bacteria in milk
}

\author{
N. Salazar, ${ }^{*}$ A. Prieto,† J. A. Leal,† B. Mayo, ${ }^{*}$ J. C. Bada-Gancedo, ${ }^{*}$ C. G. de los Reyes-Gavilán, ${ }^{*}$ \\ and P. Ruas-Madiedo*1 \\ *Instituto de Productos Lácteos de Asturias (IPLA-CSIC), Departamento de Microbiología y Bioquímica de Productos Lácteos, Carretera de \\ Infiesto s/n, 33300 Villaviciosa, Asturias, Spain \\ †Centro de Investigaciónes Biológicas (CIB-CSIC), Ramiro de Maeztu 9, 28040 Madrid, Spain
}

\begin{abstract}
This work reports on the physicochemical characterization of 21 exopolysaccharides (EPS) produced by Lactobacillus and Bifidobacterium strains isolated from human intestinal microbiota, as well as the growth and metabolic activity of the EPS-producing strains in milk. The strains belong to the species Lactobacillus casei, Lactobacillus rhamnosus, Lactobacillus plantarum, Lactobacillus vaginalis, Bifidobacterium animalis, Bifidobacterium longum, and Bifidobacterium pseudocatenulatum. The molar mass distribution of EPS fractions showed 2 peaks of different sizes, which is a feature shared with some EPS from bacteria of food origin. In general, we detected an association between the EPS size distribution and the EPS-producing species, although because of the low numbers of human bacterial EPS tested, we could not conclusively establish a correlation. The main monosaccharide components of the EPS under study were glucose, galactose, and rhamnose, which are the same as those found in food polymers; however, the rhamnose and glucose ratios was generally higher than the galactose ratio in our human bacterial EPS. All EPS-producing strains were able to grow and acidify milk; most lactobacilli produced lactic acid as the main metabolite. The lactic acid-to-acetic acid ratio in bifidobacteria was 0.7 , close to the theoretical ratio, indicating that the EPS-producing strains did not produce an excessive amount of acetic acid, which could adversely affect the sensory properties of fermented milks. With respect to their viscosity-intensifying ability, L. plantarum $\mathrm{H} 2$ and L. rhamnosus $\mathrm{E} 41$ and E43R were able to increase the viscosity of stirred, fermented milks to a similar extent as the EPS-producing Streptococcus thermophilus strain used as a positive control. Therefore, these human EPS-producing bacteria could
\end{abstract}

Received February 13, 2009.

Accepted June 1, 2009.

${ }^{1}$ Corresponding author: ruas-madiedo@ipla.csic.es be used as adjuncts in mixed cultures for the formulation of functional foods if probiotic characteristics could be demonstrated. This is the first article reporting the physicochemical characteristics of EPS isolated from human intestinal microbiota.

Key words: exopolysaccharide, human origin, Bifidobacterium, Lactobacillus

\section{INTRODUCTION}

Recently, the concept of a "functional starter" has been introduced in reference to "cultures that possess properties which contribute to food safety and/or offer one or more organoleptic, technological, nutritional, or health advantages" (Leroy and De Vuyst, 2004). In this context, some exopolysaccharide (EPS)-producing lactic acid bacteria (LAB) strains could cover both technological and health aspects. Their capability to improve the rheological characteristics of fermented milks has been proven and, more recently, health benefits have been attributed to some of these biopolymers. It is well known that the key parameters determining the viscosity and texture-intensifying capability of EPS are mainly their chemical composition, their molar mass (MM), and the structure of the repeating units (Laws and Marshall, 2001), as well as their interaction with the food protein matrix (Hassan, 2008). However, very few articles have reported on the relationship between the physicochemical characteristics of EPS and their putative health-promoting properties (Nagaoka et al., 1994; Kitazawa et al., 1998). These studies have been conducted with polymers synthesized by LAB of food origin, and to our knowledge, no data are available on the physicochemical characteristics of polymers isolated from strains of human origin. Indeed, these strains could be good candidates for studying the relationship between the EPS production phenotype and its putative involvement in their probiotic properties. In this way, we demonstrated that human-isolated Lactobacillus and Bifidobacterium strains are able to produce EPS (Ruas-Madiedo et al., 2007). 
Currently, fresh fermented and unfermented dairy products, such as milk, yogurt, ice cream, and desserts, are widely used for the delivery of probiotic strains, and their incorporation into cheeses is under development (Boylston et al., 2004; Grattepanche et al., 2008). The viability of probiotics in fermented milks has improved in recent years, but this has been to the detriment of the variability in strains used in the formulation of these foods (Gueimonde et al. 2004). These strains have been selected because they have been shown to survive well in the fermented product, but their health-promoting properties have not been taken into account. Thus, the exploration of both technological and probiotic properties is crucial for the potential application of new strains in functional food formulations.

In the current work, we aimed to study the growth and metabolic activity in milk of human isolated EPSproducing strains. This characterization could allow us to identify potential probiotic strains with appropriate technological properties for dairy applications. Indeed, in a previous work we showed that the EPS produced by these Bifidobacterium strains had the ability to modulate the intestinal microbiota, promoting a bifidogenic effect comparable with that of the prebiotic inulin (Salazar et al., 2008). Therefore, the physicochemical characteristics of EPS synthesized by these strains were analyzed to establish a preliminary classification of these biopolymers based on their MM and monosaccharide composition. In the future, this could help us to correlate the intrinsic characteristics of EPS with their putative health benefits.

\section{MATERIALS AND METHODS}

\section{Bacterial Strains and Isolation of EPS Fraction from Culture Media}

The strains of human origin used in this study (Table 1) were previously screened for EPS production and were identified by $16 \mathrm{~S}$ rRNA gene sequencing (RuasMadiedo et al., 2007). Strains were grown in MRSC broth [de Man, Rogosa, Sharpe broth (BioKar Diagnostics, Beauvais, France) supplemented with $0.25 \%$ (wt/ vol) L-cysteine (Sigma Chemical Co., St. Louis, MO)] and incubated at $37^{\circ} \mathrm{C}$ for $24 \mathrm{~h}$ under anaerobic conditions, as described previously (Salazar et al., 2008). The strain Streptococcus thermophilus ST-body-1 (Chr. Hansen, Hørsholm, Denmark), which is currently used in yogurt manufacture, was used as an EPS-producing positive control. This control strain was inoculated directly from the lyophilized powder into M-17 broth (Oxoid Ltd., Basingstoke, UK) and grown overnight at $37^{\circ} \mathrm{C}$. This culture was used to inoculate $(2 \%)$ fresh M-17 broth, which was incubated for $24 \mathrm{~h}$.
The EPS fraction of strains was isolated from the cellular biomass harvested from agar-MRSC plates. In short, strains were grown on the surface of agar-MRSC for $5 \mathrm{~d}$ under anaerobic conditions at $37^{\circ} \mathrm{C}$. The cellular biomass was collected with ultrapure water and mixed with 1 vol of $2 M \mathrm{NaOH}$. After gentle stirring overnight at room temperature, cells were removed by centrifugation and EPS from the supernatants were precipitated for $48 \mathrm{~h}$ at $4^{\circ} \mathrm{C}$ with 2 vol of absolute cold ethanol. After centrifugation $\left(10,000 \times g, 4^{\circ} \mathrm{C}, 30 \mathrm{~min}\right)$, the EPS fraction was resuspended in ultrapure water, dialyzed against ultrapure water for $3 \mathrm{~d}$ at $4^{\circ} \mathrm{C}$ in dialysis tubes (Sigma) of 12 - to $14-\mathrm{kDa}$ molecular mass cutoff, and finally freeze-dried.

\section{Distribution of EPS Fractions}

Size-exclusion chromatography (SEC) was used to determine the MM distribution of the EPS fractions. The lyophilized fractions were resuspended $(5 \mathrm{mg} / \mathrm{mL})$ in $0.1 \mathrm{M} \mathrm{NaNO}_{3}$, kept overnight under gentle stirring, and finally centrifuged $(10,000 \times g, 10 \mathrm{~min})$ before analysis. An HPLC chromatographic system composed of an Alliance 2690 module injector, a PDA 996 photodiode array detector, a 410 refractive index $(\mathbf{R I})$ detector, and Empower software (Waters, Milford, MA) was used. The separation (50- $\mu$ L-volume injection sample) was carried out in 2 columns placed in series, TSK-Gel G3000 $\mathrm{PW}_{\mathrm{XL}}$ and TSK-Gel G5000 $\mathrm{PW}_{\mathrm{XL}}$, protected with a TSK-Gel guard column (Supelco-Sigma, St. Louis, MO). The mobile phase was $0.1 \mathrm{M} \mathrm{NaNO}_{3}$ and the separations took place at $40^{\circ} \mathrm{C}$ at a flow rate of 0.45 $\mathrm{mL} / \mathrm{min}$. The EPS peaks were detected with the RI detector, and the presence of proteins was monitored through the PDA detector set at $220 \mathrm{~nm}$. Standards of dextran (Fluka-Sigma, St. Louis, MO), ranging from $5 \times 10^{3}$ to $4.9 \times 10^{6} \mathrm{Da}$, were used for quantification and MM determination. For quantification, the corresponding regression equations were calculated from 4 different concentrations of each standard $\left(R^{2} \geq 0.98\right)$, and for MM determination, the regression equation was calculated by using the elution time of 7 dextran standards of different MM $\left(\mathrm{R}^{2}=0.99\right)$. The peaks obtained via size-exclusion chromatography were arbitrarily distributed among $4 \mathrm{MM}$ ranges. The percentage of each peak was calculated with respect to the total amount of peaks detected in each EPS fraction ( $\mu$ g peak range $\times 100) /(\mu \mathrm{g}$ total peaks $)$.

\section{Monosaccharide Composition of EPS Fractions}

The EPS fractions were hydrolyzed with $0.15,1.5$, or $3 \mathrm{M}$ trifluoroacetic acid for $1 \mathrm{~h}$ at $121^{\circ} \mathrm{C}$. The products were converted into their corresponding alditol acetates 
Table 1. Bifidobacterium and Lactobacillus strains of human origin and physicochemical characteristics of their exopolysaccharide (EPS) fractions isolated from the cell biomass harvested from the surface of agar-MRSC ${ }^{1}$ plates

\begin{tabular}{|c|c|c|c|c|c|c|c|c|c|}
\hline Species & Strain & \multicolumn{4}{|c|}{ Molar mass (Da) distribution ${ }^{2}(\%)$} & \multicolumn{3}{|c|}{ Monosaccharide ratio $^{3}$} & Presence, ${ }^{4}$ other \\
\hline \multirow{2}{*}{ B. animalis } & C64MRa & - & - & 9 & 91 & 1 & 1.5 & 2.5 & - \\
\hline & E43 & - & - & 12.3 & 87.7 & 1 & 2 & 2.5 & Man \\
\hline \multirow[t]{3}{*}{ B. longum } & H73 & - & 70.7 & - & 29.3 & 2 & 1 & 2.5 & Fuc \\
\hline & L55 & - & 45.9 & - & 54.1 & 1 & 1 & 4 & - \\
\hline & $\mathrm{H} 67$ & - & 52.6 & - & 47.4 & 4 & 1 & 4 & Fuc \\
\hline \multirow{4}{*}{ B. pseudocatenulatum } & $\mathrm{C} 52$ & 10.4 & - & - & 89.6 & & 1 & 1 & Ram \\
\hline & E515 & 47.1 & - & - & 52.9 & & 1 & 2 & - \\
\hline & E63 & 38.0 & - & - & 61.9 & & 1 & 1 & - \\
\hline & H34 & - & 56.5 & - & 43.5 & & 1 & 1.5 & Fuc, NAGlc \\
\hline \multirow{3}{*}{ L. casei } & BA61 & - & - & 55.4 & 44.6 & 2 & 1 & 4 & — \\
\hline & E51 & 16.1 & - & - & 83.9 & & 1 & 2 & - \\
\hline & F72 & - & - & 58.9 & 41.1 & 2 & 1 & 2.4 & - \\
\hline L. plantarum & $\mathrm{H} 2$ & - & - & 32.3 & 67.7 & & 1 & 3 & Ram \\
\hline L. vaginalis & C32 & - & 68.6 & - & 31.4 & & 1 & 2 & Man, NAGlc \\
\hline
\end{tabular}

${ }^{1} \mathrm{MRSC}=$ de Man, Rogosa, Sharpe broth (BioKar Diagnostics, Beauvais, France) supplemented with 0.25\% (wt/vol) L-cysteine (Sigma Chemical Co., St. Louis, MO).

${ }^{2}$ Percentage calculated with respect to the total amount $(\mu \mathrm{g})$ of peaks measured by size-exclusion chromatography.

${ }^{3}$ Ram $=$ rhamnose Gal = galactose; Glc $=$ glucose.

${ }^{4}$ Content lower than $10 \%$ of the total monosaccharides. Man $=$ mannose; Fuc $=$ fucose; NAGlc $=N$-acetyl-glucosamine.

and then identified and quantified by GLC, with inositol as the internal standard (IS). The composition of neutral sugars was determined with an Autosystem instrument (Perkin-Elmer, Norwalk, CT) equipped with a flame-ionization detector, using a TR-CN100 capillary column $(30 \mathrm{~m} \times 0.25 \mathrm{~mm}, 0.2-\mu \mathrm{m}$ film thickness $)$ and a temperature program from $210(1 \mathrm{~min})$ to $240^{\circ} \mathrm{C}$ (increase of $15^{\circ} \mathrm{C} / \mathrm{min}$, with the final temperature held for $7 \mathrm{~min}$ ), using helium as the gas carrier. Injection was performed in the split mode (split ratio 50:1). The percentage of each monosaccharide was calculated with respect to the total monosaccharide content. For identification of amino sugars, sample components were analyzed by GC-MS in an Agilent 7980A-5975C instrument (Agilent Technologies Inc., Palo Alto, CA), using an HP-5 column $(30 \mathrm{~m} \times 0.25 \mathrm{~mm}, 0.2-\mu \mathrm{m}$ film thickness) and a temperature program of 170 to $210^{\circ} \mathrm{C}$, with a 1-min initial hold and increased at $2^{\circ} \mathrm{C} / \mathrm{min}$. Peaks were identified on the basis of sample retention times relative to the retention times of commercial standards and by their mass spectra.

\section{Growth of EPS-Producing Strains in Milk}

Commercial pasteurized milk (Central Lechera Asturiana, Asturias, Spain) was purchased from the super- market and was supplemented with $1 \%$ Difco skim milk (Becton Dickinson, Franklin Lakes, NJ) and $0.2 \%$ yeast extract (Biokar Diagnostics), giving a TS content of $12.5 \%$. This supplemented milk was pasteurized again at $90^{\circ} \mathrm{C}$ for 5 min. The MRSC or M-17 cultures of each strain were washed twice with sterile PBS buffer $(\mathrm{pH}$ 7.0) and were used separately to inoculate (2\%) 500 $\mathrm{mL}$ of pasteurized milk. The inoculated milks were incubated overnight $(17 \pm 1 \mathrm{~h})$ in a water bath at $37^{\circ} \mathrm{C}$ and, at the end, a sample was collected under sterile conditions for bacterial counting and $\mathrm{pH}$ measurements. Afterward, the fermented milks were cooled to approximately $18^{\circ} \mathrm{C}$ with running tap water, stirred 20 times up and down with a spoon, and stored overnight at $4^{\circ} \mathrm{C}$. Three replicated batches of milks were fermented for each strain.

For bacterial counts, serial dilutions of cultured milks were made in Ringer's solution (Merck, Darmstadt, Germany) and were deep-plated on agar-MRSC or agar-M-17. The plates were incubated at $37^{\circ} \mathrm{C}$ for 3 d under anaerobic conditions for Lactobacillus and Bifidobacterium and under aerobic conditions for Strep. thermophilus. Counts were expressed as log colonyforming units per gram and the increase in log units during milk fermentation was calculated. 


\section{Isolation of EPS from Cultured Milk and Apparent Viscosity of Stirred, Fermented Milks}

The EPS fraction was isolated from milks cultured with the EPS-producing strains of human origin. Briefly, $40 \mathrm{~g}$ of cultured milk was mixed with a TCA solution (12\% final concentration) and stirred vigorously for $45 \mathrm{~min}$ at room temperature. Precipitated bacteria and proteins were removed by centrifugation $\left(10,000 \times g, 4^{\circ} \mathrm{C}, 30 \mathrm{~min}\right)$ and $\mathrm{pH}$ of the supernatant was increased to $4.5 \pm 0.5$. Finally, supernatants were intensively dialyzed and freeze-dried as described in the previous paragraph. Given that the yeast extract added to milk could be a source of polysaccharides (mainly gluco- and galactomannans), the same procedure was used to obtain the precipitated fraction of uncultured, supplemented pasteurized milk. The EPS yield $(\mathrm{mg} / 100$ $\mathrm{mL}$ of whey) of each strain growing in milk was calculated after subtracting the precipitated fraction (15.0 \pm $1.5 \mathrm{mg} / 100 \mathrm{~mL}$ of whey) obtained from the uncultured milk.

The apparent viscosity of stirred, fermented milks was measured using a Posthumus funnel (Hellinga et al., 1989). The funnel was filled with approximately $450 \mathrm{~g}$ of stirred, fermented milk and the time (s) taken to pass the mark inside the funnel was recorded. The measurements were carried out in a chamber refrigerated at $4^{\circ} \mathrm{C}$.

\section{Lactose Consumption and Organic Acid Production in Fermented Milks}

The same HPLC chromatographic system described above was used to quantify lactose consumption and organic acid production in fermented milks. Samples for HPLC analysis were prepared as follows: $5 \mathrm{~g}$ of cultured milk was mixed with $20 \mathrm{~mL}$ of $9 \mathrm{mN} \mathrm{H}_{2} \mathrm{SO}_{4}$ and held at $37^{\circ} \mathrm{C}$ with constant shaking for $2 \mathrm{~h}$, and after centrifugation $(10,000 \times g, 20 \mathrm{~min})$, supernatants were filtered through filter paper. Sample separation was carried out in an ICSep ION-300 ion-exchange column (Transgenomic, San Jose, CA) using $8.5 \mathrm{mN} \mathrm{H}_{2} \mathrm{SO}_{4}$ as the mobile phase at $65^{\circ} \mathrm{C}$, with a flow rate of $0.4 \mathrm{~mL} /$ min. Lactose was detected with the RI detector and organic acids were detected with the PDA detector set at $210 \mathrm{~nm}$. For quantification, the regression equations $\left(\mathrm{R}^{2} \geq 0.99\right)$ were calculated by using different concentrations of the corresponding standards purchased from Fluka-Sigma. Results are expressed as millimolar concentrations.

\section{Production of Volatile Compounds in Fermented Milks}

Volatile compounds produced by lactobacilli and bifidobacteria in fermented milks were determined by means of headspace (HS) GC-MS. Samples (10 g) of fermented milk were mixed with cyclohexanone $(0.36 \mathrm{mg} /$ $\mathrm{mL}$ ) as the IS and were placed into glass tubes sealed with rubber and metallic caps. They were analyzed in a $6890 \mathrm{~N}$ Agilent gas chromatograph coupled with a G1888 series HS automatic injector and with a 5975B inert MS detector (Agilent). Data were collected and analyzed with ChemStation software (Agilent). Samples in the HS were held at $50^{\circ} \mathrm{C}$ for 30 min under stirring and were then separated in an HP-Innovax column (60 $\mathrm{m} \times 0.25 \mathrm{~mm}, 0.25-\mu \mathrm{m}$ film thickness; Agilent). The injector temperature was maintained at $220^{\circ} \mathrm{C}$ and the split ratio was 20:1. The chromatographic conditions were $35^{\circ} \mathrm{C}$ for $5 \mathrm{~min}, 100^{\circ} \mathrm{C}$ (increased at $5^{\circ} \mathrm{C} / \mathrm{min}$ ) final temperature for $10 \mathrm{~min}$, and $240^{\circ} \mathrm{C}$ (increased at $8^{\circ} \mathrm{C} /$ $\mathrm{min}$ ) final temperature for $5 \mathrm{~min}$, with helium as the carrier gas. The electron impact energy of the MS detector was set to $70 \mathrm{eV}$ and data were collected within the 20- to 250-amu range (at 3.12 scans/s). Volatile compounds were identified by comparing their mass spectra with those held in the Wiley 138 library (Agilent) and by comparing their retention times with those of the corresponding IS (Fluka-Sigma). The peaks were quantified as the relative total ionic count abundance with respect to the IS. The concentration $(\mu \mathrm{g} / \mathrm{mL})$ of each volatile compound was calculated by using linear regression equations $\left(R^{2}>0.99\right)$ of the corresponding standards.

\section{RESULTS AND DISCUSSION}

\section{Characterization of EPS Produced by Human Bifidobacterium and Lactobacillus Strains}

A broad MM distribution, ranging from approximately $10^{3}$ to $5 \times 10^{6} \mathrm{Da}$, of the EPS fractions isolated from agar-MRSC plates of Bifidobacterium and Lactobacillus strains of human intestinal origin were detected. In addition, within each EPS fraction, more than one peak varying in size was monitored (Table 1). An arbitrary classification of MM ranges was then established as follows: M1, $>10^{6}$ Da; M2, $10^{5}$ to $10^{6}$ Da; M3, $10^{4}$ to $10^{5}$ Da; and M4, $<10^{4}$ Da. Most EPS fractions showed 2 different MM peaks and all of them included the smaller peak range, in some cases with this range being present at the highest (more than $80 \%$ ) proportion. The 4 Lactobacillus plantarum strains as well as the Lactobacillus casei BA61 and F72 strains showed a second peak within the M3 range. However, L. casei E51 was the only lactobacillus presenting a peak $\left(2 \times 10^{6} \mathrm{Da}\right)$ of the highest M1, whereas in the 2 Lactobacillus rhamnosus strains and the Lactobacillus vaginalis strain, the M2 peak was detected. These data indicated a different pattern of EPS MM distribution 
within each Lactobacillus species. A similar behavior was also noted for the Bifidobacterium species. Thus, the 2 Bifidobacterium animalis strains had EPS with a second peak in the M3 range; in 3 out of 4 Bifidobacterium longum strains the M2 range was detected; and most Bifidobacterium pseudocatenulatum strains presented the M1 highest range. However, the scarce number of strains analyzed for each species did not allow us to definitively establish a direct correlation between the EPS size distribution and the EPS-producing species. As far as we are aware, there are no data in the literature that report the MM values of EPS synthesized by lactobacilli of human origin. Mozzi et al. (2006) collected data on EPS from several mesophilic and thermophilic Lactobacillus strains of food origin, and most showed MM values lower than $10^{6} \mathrm{Da}$, as was evidenced in our EPS strains of human origin. None of the food strains presented more than one MM peak simultaneously; however, the EPS fraction produced by several strains of Lactobacillus delbrueckii ssp. bulgaricus, Strep. thermophilus, and Lactococcus lactis ssp. cremoris as well as that synthesized by Lactobacillus pentosus LPS26 presented 2 EPS of different MM simultaneously (Grobben et al., 1997; Degeest and De Vuyst, 1999; Petry et al., 2003; Vaningelgem et al., 2004; Ruas-Madiedo et al., 2005; Sánchez et al., 2006). Thus, the production of 2 EPS peaks of different sizes seems to be a relatively common characteristic among LAB of food and intestinal origin. With respect to the EPS synthesized by Bifidobacterium, data in the literature are scarce regarding their MM distribution (Nagaoka et al., 1995; Roberts et al., 1995; Hosono et al., 1997). The production of 2 EPS fractions of different sizes has been detected as well in B. longum and Bifidobacterium infantis (Abbad-Andaloussi et al., 1995; Tone-Shimokawa et al., 1996). It has been reported that variations in the culture conditions (nitrogen and carbon sources, $\mathrm{pH}$, temperature, etc.) could modify the ratio of high to low MM (Degeest and De Vuyst, 1999) or could induce the production of 2 EPS of different chemical or structural compositions (Cerning et al., 1994; Petry et al., 2000; Wang and $\mathrm{Bi}, 2008)$. It has been also postulated that the occurrence of more than one EPS fraction produced by a single strain could be due to partial hydrolysis of the highest peak as a consequence of prolonged fermentation (De Vuyst et al., 1998). We cannot exclude the possibility of partial hydrolysis of our EPS after the producing bacteria were incubated on the surface of agar-MRSC for $5 \mathrm{~d}$. In fact, in MRSC broth we were able to cultivate the biomass collected from the solid medium after this period. However, part of the microbial population may not have been viable or could even have been dead, and thus could have released glycolytic enzymes. In spite of this, a relative long incubation period $(5 \mathrm{~d})$ was used in our case because of the generally slow growth of strains of human origin and the need to obtain optimal biomass production to provide enough EPS for their physicochemical characterization.

Regarding the chemical composition (Table 1), the monosaccharides galactose and glucose were present in all polymers and rhamnose was present in half of them. These are also the 3 major sugar components of EPS isolated from food environments. Mannose, fucose, and $N$-acetyl-glucosamine were detected in minor proportions in 4 out of the 11 Bifidobacterium strains and in $L$. vaginalis $\mathrm{C} 32$. $N$-Acetyl-aminated sugars are also commonly found in EPS from LAB, whereas fucose and mannose have been described in only a few strains (Ruas-Madiedo et al., 2009). The ratio among the major monosaccharides varied depending on the strain, and a species-associated pattern was not evidenced for most of them. In general, for all EPS, with the exception of the $2 \mathrm{~B}$. animalis strains, galactose was present at a lower ratio than glucose and rhamnose, when this last monosaccharide was present. In contrast, in EPS from lactobacilli of food origin, galactose is often found at the same or a higher proportion than the other monosaccharides (Mozzi et al., 2006; Ruas-Madiedo et al., 2009). In the EPS produced by our B. animalis and B. longum strains (with the exception of strain E44) of human origin, the monosaccharide rhamnose was present, whereas in B. pseudocatenulatum it was absent. Moreover, strains B. longum $\mathrm{H} 73$ and $\mathrm{H} 67$ presented a high content of rhamnose, which was also detected for the EPS from most $L$. casei and L. rhamnosus strains. In this regard, it is interesting to note that the polymer composition of 25 EPS produced by LAB strains from food revealed that only 7 (28\%) had rhamnose in their composition (Ruas-Madiedo et al., 2009), whereas the EPS produced by our strains of human origin presented a higher occurrence of rhamnose (11 out of 21 strains, $52 \%$ ) and also in higher proportions (ratios above 1). In this regard, the high rhamnose content of EPS from Bifidobacterium has been related to the capacity for protection against gastric ulcers induced in rats (Nagaoka et al., 1994). Chemical characterization of the human bacterial EPS carried out in this work confirmed our previous results related to the screening of genes involved in EPS synthesis (Ruas-Madiedo et al., 2007), which revealed that they were heteropolysaccharides. Finally, it is necessary to exercise caution when using laboratory media for analyzing EPS produced by intestinal bacteria. In fact, environmental conditions in the laboratory and gut are drastically different, and culturing conditions are known to have a major influence on the types of EPS produced. Hence, differences in EPS 
maybe expected between those found in our study and those actually produced in the gut environment by the same strain.

\section{Growth and Metabolic Activity of EPS-Producing Strains of Human Origin in Milk}

The EPS-producing strains isolated from human microbiota were grown in pasteurized milk supplemented with $0.2 \%$ of yeast extract that was added to increase the available nitrogen source to allow these strains to grow in milk as single cultures. The $\mathrm{pH}$ values and the increase in log colony-forming units per gram after 17 $\pm 1 \mathrm{~h}$ of incubation at $37^{\circ} \mathrm{C}$ are depicted in Figure 1. The initial $\mathrm{pH}$ of milk was $6.5 \pm 0.2$, and all lactobacilli were able to decrease the $\mathrm{pH}$ below 4.5 , except $L$. vaginalis $\mathrm{C} 32$, which reached a value of only 5.1. The $\mathrm{pH}$ of milks cultured with Bifidobacterium strains presented values of approximately 4.5 , with the exception of milks with B. longum L55 and E44, which displayed lower values, and those cultured with $B$. animalis C64MRa and E43, which were above 5.0. Regarding the ability of bacteria to grow in milk, all strains increased their counts by more than $1.5 \mathrm{log} \mathrm{cfu} / \mathrm{g}$ compared with the initial levels. Among lactobacilli, the L. casei strains reached the highest counts, followed by L. rhamnosus and L. plantarum. Remarkably, several Bifidobacterium strains were able to increase their counts by more than $2.5 \log$ units. Contrary to expectations, B. animalis strains showed the poorest ability to grow in milk, which was in accordance with their low capacity to produce organic acids.

Figure 2 shows lactose consumption and organic acid production in milks fermented with the EPS-producing strains of human origin. Milks cultured with $B$. animalis C64MRa and E43 presented the lowest lactose consumption, and consequently had the lowest lactic and acetic acid production, as compared with the other strains. The initial lactose content in the pasteurized milk was $28.7 \pm 2.4 \mathrm{~m} M$ and the consumption ranged between $8 \%$ (for B. animalis E43) and 36\% (for L. plantarum $\mathrm{C} 64 \mathrm{MRb})$, showing wide variability among strains. The average lactic acid-to-acetic acid ratio obtained in these fermented milks was $0.85 \pm 0.14$ for Bifidobacterium and $4.51 \pm 1.12$ for Lactobacillus. From a sensory point of view, the production of no excessively high amounts of acetic acid as compared with lactic acid is a desirable characteristic for preserving the sensory properties of fermented milk. Ethanol was produced in variable amounts depending on the strain (Table 2). Acetaldehyde and diacetyl were also detected in most milks cultured with bifidobacteria. Moderate production of acetic acid and a very low level of ethanol were detected in milks fermented with the L. casei, L. rhamnosus, and L. plantarum groups, with most glucose (coming from the hydrolysis of lactose) being converted into lactic acid. The strain L. vaginalis $\mathrm{C} 32$ had a different behavior because it was the highest producer of ethanol $(277 \mu \mathrm{g} / \mathrm{mL}$ on average) and the lowest producer of lactic acid among the lactobacilli, which is in accordance with the heterofermentative metabolism of this species (Embely et al., 1989). The ability of our strains to grow in milk is strain dependent, as was indicated previously for other probiotic Bifidobacterium and Lactobacillus strains (Gilliland et al., 2002; Ostlie, et al., 2003). Milk composition is known to influence the growth capacity of the strains (Kehagias et al., 2008). This could be related to the different AA availability among the milk types. Because, in our case, a fast-use nitrogen source (yeast extract) was available, other factors (such as variation in $\beta$-galactosidase activity, carbohydrate and peptide AA transport systems, oxygen, and $\mathrm{pH}$ tolerance, etc.) underlying differences in proteolytic activity could account for the different capacities of our strains to grow in milk. Variations in the levels of metabolites produced during milk fermentation were also detected among our strains, as indicated previously by other authors (Baron et al., 2000; Ostlie et al., 2003). In this way, it is well known that the metabolic profile of potential probiotic strains growing in milk correlates directly with the sensory characteristics of the product, thereby being an important selection criterion for the formulation of functional dairy foods. Finally, this study was conducted to select strains with potential application for human consumption. However, because the yeast extract cannot be included in the formulation of fermented milks, the use of starters (Strep. thermophilus, L. delbrueckii ssp. bulgaricus, or both) would be the next step in the assay of mixed fermentations for application in the dairy industry.

The apparent (Posthumus) viscosity of milks cultured with some EPS-producing strains of human origin, as well as the amount of EPS fraction purified from the fermented milks, is presented in Table 3. The amount of EPS produced in milk by the strains characterized was low. It is worth mentioning that this value could have been underestimated because of the subtraction of the precipitated fraction from the uncultured milk. However, this was necessary to avoid the quantification of possible polysaccharides coming from the small amount of yeast extract added to the milk, which could be coprecipitated during the EPS purification process. In general, the viscosity-intensifying capability of the strains of human origin was very scarce, and most strains showed values of apparent viscosity lower than 35 S (data not shown). Only 3 of our Lactobacillus strains conferred to the fermented milks a smooth and creamy consistency comparable with that of the 
EPS-producing Strep. thermophilus strain used as a control (Table 3). These were L. rhamnosus E41 and E43R and L. plantarum H2. Interestingly, the same strains were also able to increase the apparent viscosity of the stirred, fermented milks, although their values were lower than that of Strep. thermophilus ST-body-1. Among these 3 lactobacilli, only L. plantarum $\mathrm{H} 2$ increased the viscosity of the fermented milk by produc- ing a low amount of EPS similar to those produced by Strep. thermophilus, with their yield being lower than that of the L. rhamnosus E41 and E43R strains but with their viscosity-intensifying ability being higher. Other intrinsic characteristics of EPS beyond the concentration reached in milk could also account for the increase in viscosity of milks fermented with the EPS-producing strains of human origin (Laws and Marshall, 2001).
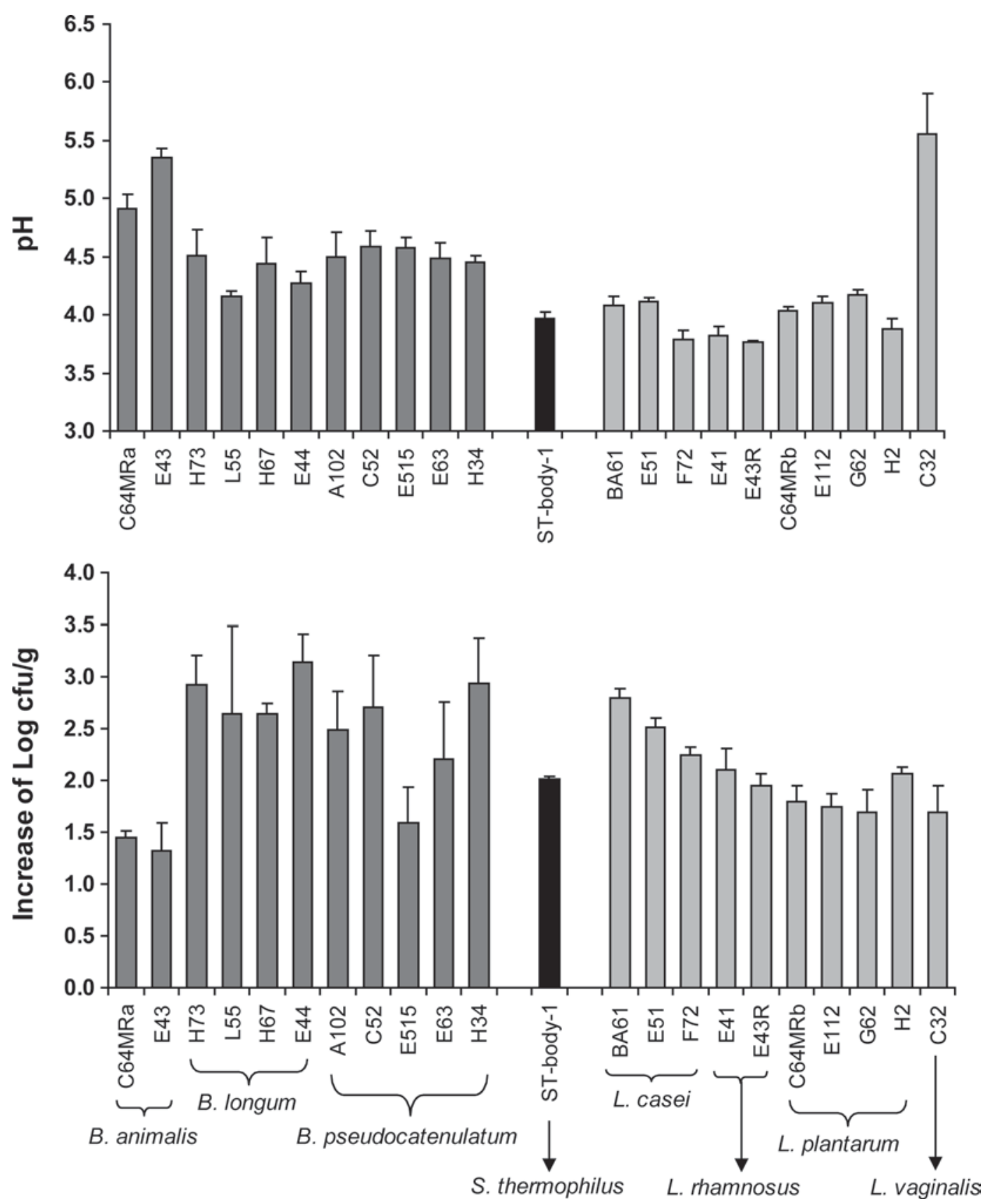

Figure 1. The $\mathrm{pH}$ values of milks fermented with exopolysaccharide (EPS)-producing Bifidobacterium and Lactobacillus strains of human origin and increase in $\log$ colony-forming units per gram after incubation at $37^{\circ} \mathrm{C}$ for $17 \pm 1 \mathrm{~h}$. The strain Streptococcus thermophilus ST-body- 1 , which is used in yogurt manufacture, was used as an EPS-producing strain control. 

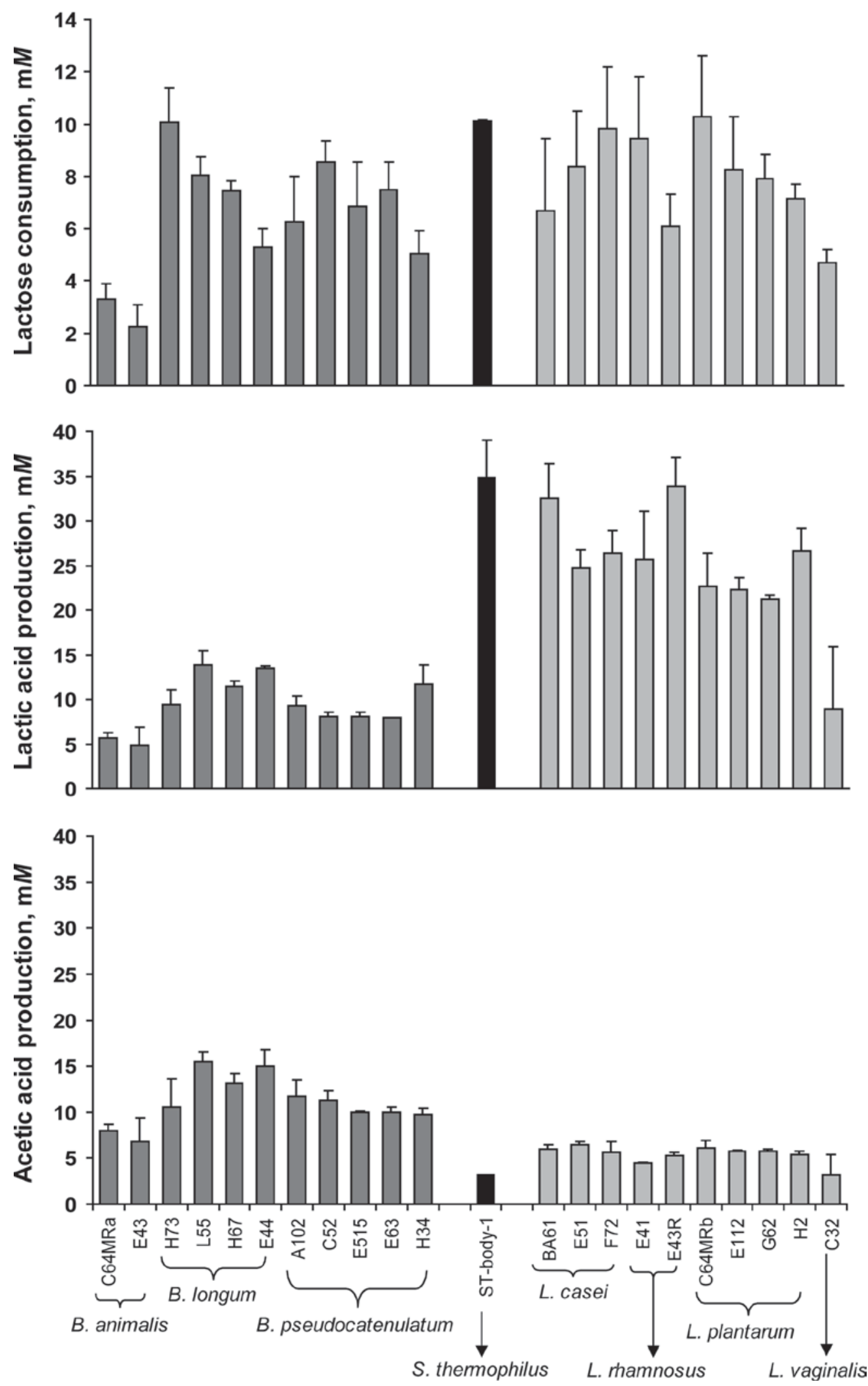

Figure 2. Mean values $(\mathrm{m} M)$ for lactose consumption and production of lactic acid and acetic acid in milks fermented with exopolysaccharide (EPS)-producing Bifidobacterium and Lactobacillus strains of human origin at $37^{\circ} \mathrm{C}$ for $17 \pm 1$ h. The strain Streptococcus thermophilus ST-body-1, which is used in yogurt manufacture, was used as an EPS-producing strain control. 
Table 2. Volatile compounds produced (mean $\pm \mathrm{SD}, \mu \mathrm{g} / \mathrm{mL}$ ) in milks fermented with exopolysaccharide (EPS)-producing Bifidobacterium and Lactobacillus strains of human origin

\begin{tabular}{|c|c|c|c|c|}
\hline Species & Strain & Acetaldehyde $^{1}$ & Diacetyl & Ethanol \\
\hline Uncultured milk & - & $0.27 \pm 0.06$ & $0.19 \pm 0.01$ & $2.17 \pm 0.04$ \\
\hline \multirow[t]{2}{*}{ B. animalis } & C64MRa & $21.86 \pm 1.24$ & $0.99 \pm 0.16$ & $47.91 \pm 5.81$ \\
\hline & $\mathrm{E} 43$ & ND & $2.00 \pm 0.58$ & $167.25 \pm 46.39$ \\
\hline \multirow[t]{4}{*}{ B. longum } & $\mathrm{H} 73$ & $6.20 \pm 0.83$ & $3.34 \pm 0.57$ & $40.50 \pm 3.76$ \\
\hline & L55 & $10.04 \pm 1.54$ & $1.75 \pm 0.20$ & $43.00 \pm 3.61$ \\
\hline & H67 & $14.70 \pm 0.72$ & $4.35 \pm 0.33$ & $51.01 \pm 1.28$ \\
\hline & $\mathrm{E} 44$ & $7.67 \pm 0.93$ & $1.22 \pm 0.01$ & $37.43 \pm 4.05$ \\
\hline \multirow[t]{5}{*}{ B. pseudocatenulatum } & A102 & $16.43 \pm 0.28$ & $3.32 \pm 1.41$ & $35.80 \pm 2.51$ \\
\hline & C52 & $12.35 \pm 5.78$ & $2.41 \pm 0.21$ & $31.75 \pm 0.88$ \\
\hline & E515 & $14.30 \pm 0.55$ & $3.72 \pm 1.69$ & $30.48 \pm 5.7$ \\
\hline & E63 & ND & $3.45 \pm 0.18$ & $25.80 \pm 5.72$ \\
\hline & H34 & $11.48 \pm 5.74$ & $5.96 \pm 3.42$ & $30.75 \pm 12.15$ \\
\hline \multirow{3}{*}{ L. casei } & BA61 & ND & $0.08 \pm 0.01$ & $18.37 \pm 0.43$ \\
\hline & E51 & ND & $1.35 \pm 0.30$ & $35.32 \pm 0.70$ \\
\hline & F72 & ND & $0.19 \pm 0.12$ & $9.45 \pm 1.45$ \\
\hline \multirow[t]{2}{*}{ L. rhamnosus } & $\mathrm{E} 41$ & ND & $0.32 \pm 0.04$ & $13.53 \pm 0.87$ \\
\hline & E43R & ND & $0.25 \pm 0.05$ & $12.64 \pm 0.46$ \\
\hline \multirow[t]{4}{*}{ L. plantarum } & C64MRb & ND & $0.31 \pm 0.10$ & $4.09 \pm 1.53$ \\
\hline & E112 & ND & $0.54 \pm 0.34$ & $11.59 \pm 0.19$ \\
\hline & G62 & $1.62 \pm 1.02$ & $0.44 \pm 0.18$ & $3.28 \pm 0.39$ \\
\hline & $\mathrm{H} 2$ & ND & $0.43 \pm 0.22$ & $13.79 \pm 0.35$ \\
\hline L. vaginalis & $\mathrm{C} 32$ & ND & $1.92 \pm 1.32$ & $277.09 \pm 125.73$ \\
\hline Streptococcus thermophilus ${ }^{2}$ & ST-body-1 & $9.38 \pm 0.56$ & $0.75 \pm 0.11$ & $4.92 \pm 0.79$ \\
\hline
\end{tabular}

${ }^{1} \mathrm{ND}=$ level under the detection limit.

${ }^{2}$ The strain Strep. thermophilus ST-body-1 was used as an EPS-producing strain control.

The MM of an EPS strongly influences the viscosity of fermented milks made with EPS-producing strains and, in general, polymers having high MM can produce fermented milks with higher viscosity (Ruas-Madiedo et al., 2009). However, in the present study we could not correlate the MM values obtained in MRSC medium with the viscosity of the fermented milk because, as stated previously, the MM and chemical composition of EPS could greatly vary depending on the culture conditions. Finally, factors such as interactions between the EPS and the milk protein network (Hassan, 2008) or the acidification rate of the strains in milk (Lucey and Singh, 1998), among others, could affect the viscosity of the stirred, fermented milk. However, because our strains E41, E43R, and $\mathrm{H} 2$ of human origin and the control strain reached similar final $\mathrm{pH}$ after the same incubation period $(3.82 \pm 0.08,3.76 \pm 0.02,3.88$ \pm 0.09 , and $3.97 \pm 0.06$, respectively), differences in acidification could have not accounted for variations in the viscosity of the fermented milks.

\section{CONCLUSIONS}

Our EPS-producing strains of human origin presented higher rhamnose content than strains of food origin studied previously by other authors. In the future, this characteristic could be correlated with a putative biological effect at the intestinal mucosal level. Currently, it is not possible to reproduce the gut conditions in the laboratory to study EPS production in this environment. Therefore, the use of laboratory media is a valuable technique for undertaking the preliminary characterization of polymers of new origin. However, given the influence of the culturing conditions on both

Table 3. Exopolysaccharide (EPS) production and apparent (Posthumus) viscosity (mean \pm SD) of stirred milks fermented with some EPS-producing Lactobacillus strains of human origin

\begin{tabular}{llcc}
\hline Species & Strain & Viscosity $(\mathrm{s})$ & EPS fraction $^{1}(\mathrm{mg} / 100 \mathrm{~mL}$ of whey) \\
\hline L. rhamnosus & E41 & $63.3 \pm 3.7$ & 29.0 \\
& E43R & $69.0 \pm 7.9$ & $51.4 \pm 11.4$ \\
L. plantarum & H2 & $72.0 \pm 24.0$ & 18.9 \\
Streptococcus thermophilus & ST-body-1 & $143.3 \pm 20.8$ & $15.5 \pm 0.2$ \\
\hline
\end{tabular}

${ }^{1}$ The values were calculated after subtracting the precipitated fraction isolated from nonfermented milk.

${ }^{2}$ The strain Strep. thermophilus ST-body-1 was used as an EPS-producing strain control with a high viscosityintensifying capability. 
the MM and chemical composition of EPS, the characterization of EPS produced in the gut environment remains a challenge for the future.

For application in the dairy industry, it is important to know the growth capability and metabolic activity of these microorganisms in milk. Our study indicates that 3 EPS-producing lactobacilli, L. rhamnosus E41, $L$. rhamnosus E43R, and mainly L. plantarum $\mathrm{H} 2$, could have good technological properties. They all grew and acidified milk; additionally, they were able to increase the viscosity of and confer a desirable texture to the fermented product. Most bifidobacteria were able to grow and acidify milk without producing an excessive amount of acetic acid, which would not be a desirable sensory characteristic in fermented milks. Therefore, both lactobacilli and bifidobacteria could be used as adjuncts in mixed cultures for the formulation of functional foods if they presented probiotic characteristics.

\section{ACKNOWLEDGMENTS}

This work was financed by the "Fondo Europea para el Desarrolo Regional" (FEDER, European Union, Brussels, Belgium) and the Spanish "Plan Nacional de I+D+i" (MICINN, Spanish Ministry of Science and Innovation, Madrid, Spain) through projects AGL200603336 and AGL2007-62736. N. Salazar was funded by predoctoral "Formacion de Personal Investigador" (FPI) fellowship from MICINN. Isabel Cuesta (IPLACSIC) and Ana Hernández-Barranco are acknowledged for their excellent technical assistance in the HPLC and GC-MS analysis. The authors are grateful to Chr. Hansen (Hørsholm, Denmark) for kindly supplying the Strep. thermophilus ST-body-1 strain for research purposes.

\section{REFERENCES}

Abbad-Andaloussi, S., H. Talbaoui, R. Marczak, and R. Bonaly. 1995. Isolation and characterization of exocellular polysaccharide produced by Bifidobacterium longum. Appl. Microbiol. Biotechnol. 43:995-1000.

Baron, M., D. Roy, and J. C. Vuillemard. 2000. Biochemical characteristics of fermented milk produced by mixed-cultures of lactic starters and bifidobacteria. Lait 80:465-478.

Boylston, T. D., C. G. Vinderola, H. B. Ghoddusi, and J. A. Reinheimer. 2004. Incorporation of bifidobacteria into cheeses: Challenges and rewards. Int. Dairy J. 14:375-387.

Cerning, J., C. M. G. C. Renard, J. F. Thibault, C. Bouillanne, M. Landon, M. Desmazeaud, and L. Topisirovic. 1994. Carbon source requirements for exopolysaccharide production by Lactobacillus casei CG11 and partial structure analysis of the polymer. Appl. Environ. Microbiol. 60:3914-3919.

De Vuyst, L., F. Vanderveken, S. van de Ven, and B. Degeest. 1998. Production by and isolation of exopolysaccharides from Streptococcus thermophilus grown in a milk medium and evidence of their growth-associated biosynthesis. J. Appl. Microbiol. 84:1059-1068.

Degeest, B., and L. De Vuyst. 1999. Indication that the nitrogen source influences both amount and size of exopolysaccharides produced by Streptococcus thermophilus LY03 and modelling of the bacterial growth and exopolysaccharide production in a complex medium. Appl. Environ. Microbiol. 65:2863-2870.

Embely, T. M., N. Faquir, W. Bossart, and M. D. Collins. 1989. Lactobacillus vaginalis sp. nov. from the human vagina. Int. J. Syst. Bacteriol. 39:368-370.

Gilliland, S. E., S. S. Reully, G. B. Kim, and H. S. Kim. 2002. Viability during storage of selected probiotic lactobacilli and bifidobacteria in a yogurt-like product. J. Food Sci. 67:3091-3095.

Grattepanche, F., S. Miescher-Schwenninger, L. Meile, and C. Lacroix. 2008. Recent developments in cheese cultures with protective and probiotic functionalities. Dairy Sci. Technol. 88:421-444.

Grobben, G. J., W. H. M. van Casteren, H. A. Schols, A. Oosterveld, G. Sala, M. R. Smith, J. Sikkema, and J. A. M. de Bont. 1997. Analysis of the exopolysaccharides produced by Lactobacillus delbrueckii subsp. bulgaricus NCFB2772 grown in continuous culture on glucose or fructose. Appl. Microbiol. Biotechnol. 48:516-521.

Gueimonde, M., S. Delgado, B. Mayo, P. Ruas-Madiedo, A. Margolles, and C. G. de los Reyes-Gavilán. 2004. Viability and diversity of probiotic Lactobacillus and Bifidobacterium populations included in commercial fermented milks. Food Res. Int. 37:839-850.

Hassan, A. N. 2008. ADSA Foundation Scholar Award: Possibilities and challenges of exopolysaccharide-producing lactic cultures in dairy foods. J. Dairy Sci. 91:1282-1298.

Hellinga, C., D. J. Somesen, and J. P. J. M. Koenraads. 1989. Viscosity of stirred yoghurt: Modern techniques useful in analysing and improving routine measurements. Neth. Milk Dairy J. 40:217240

Hosono, A., J. Lee, A. Ametani, M. Natsume, M. Hirayama, T. Adachi, and S. Kaminogawa. 1997. Characterization of a watersoluble polysaccharide fraction with immunopotentiating activity from Bifidobacterium adolescentis M101-4. Biosci. Biotechnol. Biochem. 61:312-316.

Kehagias, C., J. Csapó, S. Konteles, E. Kolokitha, S. Koulouris, and Z. Csapó-Kiss. 2008. Support of growth and formation of D-amino acids by Bifidobacterium longum in cows', ewes', goats' milk and modified whey powder products. Int. Dairy J. 18:396-402.

Kitazawa, H., T. Harata, J. Uemura, T. Saito, T. Kanebo, and T. Ithoh. 1998. Phosphate group requirement for mitogenic activation of lymphocytes by an extracellular phosphopolysaccharide from Lactobacillus delbrueckii ssp. bulgaricus. Int. J. Food Microbiol. 40:169-175.

Laws, A. P., and V. M. Marshall. 2001. The relevance of exopolysaccharides to the rheological properties in milk fermented with ropy strains of lactic acid bacteria. Int. Dairy J. 11:709721 .

Leroy, F., and L. De Vuyst. 2004. Lactic acid bacteria as functional starter cultures for the food fermentation industry. Trends Food Sci. Technol. 15:67-78.

Lucey, J. A., and H. Singh. 1998. Formation and physical properties of acid milk gels: A review. Food Res. Int. 30:529-542.

Mozzi, F., F. Vaningelgem, E. M. Hébert, R. van der Meulen, M. R. Foulquié-Moreno, G. Font de Valdez, and L. De Vuyst. 2006. Diversity of heteropolysaccharide-producing lactic acid bacterium strains and their biopolymers. Appl. Environ. Microbiol. 72:44314435.

Nagaoka, M., S. Hashimoto, T. Watanabe, T. Yokokura, and Y. Mori. 1994. Anti-ulcer effects of lactic acid bacteria and their cell wall polysaccharides. Biol. Pharm. Bull. 17:1012-1017.

Nagaoka, M., H. Shibata, I. Kimura, S. Hashimoto, K. Kimura, H. Sawada, and T. Yokokura. 1995. Structural studies on a cell wall polysaccharide from Bifidobacterium longum YIT4028. Carbohydr. Res. 274:245-249.

Ostlie, H. M., M. H. Helland, and J. A. Narvhus. 2003. Growth and metabolism of selected strains of probiotic bacteria in milk. Int. J. Food Microbiol. 87:17-27.

Petry, S., S. Furlan, M. A. Crepeau, J. Cerning, and M. Desmazeaud. 2000. Factors affecting the exocellular polysaccharide production by Lactobacillus delbrueckii subsp. bulgaricus grown in a chemically defined medium. Appl. Environ. Microbiol. 66:3427-3431. 
Petry, S., S. Furlan, E. Waghorne, L. Saulnier, J. Cerning, and E. Maguin. 2003. Comparison of the thickening properties of four Lactobacillus delbrueckii subsp. bulgaricus strains and physicochemical characterization of their exopolysaccharides. FEMS Microbiol. Lett. 221:285-291.

Roberts, C. M., W. F. Fett, S. F. Osman, C. Wijey, J. V. O'Connor, and D. G. Hoover. 1995. Exopolysaccharide production by Bifidobacterium longum BB-79. J. Appl. Bacteriol. 78:463-468.

Ruas-Madiedo, P., A. Alting, and P. Zoon. 2005. Effect of exopolysaccharides and proteolytic activity of Lactococcus lactis subsp. cremoris strains on the viscosity and structure of fermented milks. Int. Dairy J. 15:155-164.

Ruas-Madiedo, P., J. A. Moreno, N. Salazar, S. Delgado, B. Mayo, A. Margolles, and C. G. de los Reyes-Gavilán. 2007. Screening of exopolysaccharide-producing Lactobacillus and Bifidobacterium strains isolated from the human intestinal microbiota. Appl. Environ. Microbiol. 73:4385-4388.

Ruas-Madiedo, P., N. Salazar, and C. G. de los Reyes-Gavilán. 2009 Biosynthesis and chemical composition of exopolysaccharides produced y lactic acid bacteria. Pages 279-310 in Bacterial Polysaccharides: Current Innovations and Future Trends. M. Ullrich, ed. Caister Academic Press, Norwich, UK.
Salazar, N., M. Gueimonde, A. M. Hernández-Barranco, P. RuasMadiedo, and C. G. de los Reyes-Gavilán. 2008. Exopolysaccharides produced by intestinal Bifidobacterium strains act as fermentable substrates for human intestinal bacteria. Appl. Environ. Microbiol. $74: 4737-4745$

Sánchez, J. I., B. Martínez, R. Guillén, R. Jiménez-Díaz, and A. Rodríguez. 2006. Culture conditions determine the balance between two different exopolysaccharides produced by Lactobacillus pentosus LPS26. Appl. Environ. Microbiol. 72:7495-7502.

Tone-Shimokawa, Y., T. Toida, and T. Kawashima. 1996. Isolation and structural analysis of polysaccharide containing galactofuranose from the cell walls of Bifidobacterium infantis. J. Bacteriol. $178: 317-320$.

Vaningelgem, F., M. Zamfir, F. Mozzi, T. Adriany, M. Vancanneyt, J. Swings, and L. De Vuyst. 2004. Biodiversity of exopolysaccharides produced by Streptococcus thermophilus strains is reflected in their production and their molecular functional characteristics. Appl. Environ. Microbiol. 70:900-912.

Wang, M., and J. Bi. 2008. Modification of characteristics of kefiran by changing the carbon source of Lactobacillus kefiranofaciens. J. Sci. Food Agric. 88:763-769. 